\title{
TU/e EmonOWEN

\section{Droplet break-up in a stirred water-in-oil emulsion in the presence of emulsifiers}

\section{Citation for published version (APA):}

Groeneweg, F., Dieren, van, F., \& Agterof, W. G. M. (1994). Droplet break-up in a stirred water-in-oil emulsion in the presence of emulsifiers. Colloids and Surfaces A: Physicochemical and Engineering Aspects, 91(1-2), 207214. https://doi.org/10.1016/0927-7757\%2894\%2902913-X, https://doi.org/10.1016/0927-7757(94)02913-X

DOI:

10.1016/0927-7757\%2894\%2902913-X

10.1016/0927-7757(94)02913-X

Document status and date:

Published: 01/01/1994

\section{Document Version:}

Publisher's PDF, also known as Version of Record (includes final page, issue and volume numbers)

\section{Please check the document version of this publication:}

- A submitted manuscript is the version of the article upon submission and before peer-review. There can be important differences between the submitted version and the official published version of record. People interested in the research are advised to contact the author for the final version of the publication, or visit the $\mathrm{DOI}$ to the publisher's website.

- The final author version and the galley proof are versions of the publication after peer review.

- The final published version features the final layout of the paper including the volume, issue and page numbers.

Link to publication

\section{General rights}

Copyright and moral rights for the publications made accessible in the public portal are retained by the authors and/or other copyright owners and it is a condition of accessing publications that users recognise and abide by the legal requirements associated with these rights.

- Users may download and print one copy of any publication from the public portal for the purpose of private study or research.

- You may not further distribute the material or use it for any profit-making activity or commercial gain

- You may freely distribute the URL identifying the publication in the public portal.

If the publication is distributed under the terms of Article 25fa of the Dutch Copyright Act, indicated by the "Taverne" license above, please follow below link for the End User Agreement:

www.tue.nl/taverne

Take down policy

If you believe that this document breaches copyright please contact us at:

openaccess@tue.nl

providing details and we will investigate your claim. 


\title{
Droplet break-up in a stirred water-in-oil emulsion in the presence of emulsifiers
}

\author{
F. Groeneweg *, F. van Dieren, W.G.M. Agterof \\ Unilever Research Laboratorium, Olivier van Noortlaan 120, 3133 AT Vlaardingen, The Netherlands
}

Received 7 February 1994; accepted 21 April 1994

\begin{abstract}
Scaling laws for droplet break-up in stirred emulsifier-containing water-in-oil emulsions with dispersed volume fractions up to $70 \%$ were evaluated. The emulsions were stirred with a standard turbine impeller and the droplet diameters were determined as a function of time both microscopically and via turbidity measurements. The droplet size was found to decrease very slowly: a steady state was reached after 1-2 h. In emulsions without emulsifier the steady state droplet diameters were found to be in agreement with predicted values. Emulsions with emulsifier showed a bimodal size distribution with a very large number of very small droplets. The average diameter of the "coarse part" of the size distribution could be described reasonably well with the droplet break-up relationships provided that the equilibrium interfacial tension was applied, indicating that the transport of emulsifier was sufficiently fast to maintain (nearly) equilibrium adsorption during the deformation of the droplet. The very small droplets could possibly be formed by tip streaming: the flow pushes the emulsifier to the tips of the droplet, resulting in a very low interfacial tension locally which leads to a stream of very small droplets.
\end{abstract}

Keywords: Droplet break-up; Emulsification; Emulsifiers; Stirred vessel; Tip streaming

\section{Introduction}

The size of the droplets in food emulsions, such as mayonnaise and margarine, is very important with respect to their properties. Therefore an understanding of how this droplet size depends on the composition and process conditions is of paramount importance. In general the size will be determined by the balance between droplet breakup and coalescence. This balance is changed by the presence of an emulsifier. In most investigations in the literature the continuous phase has a low viscosity (the inertia-dominated situation), while a continuous oil phase with increased viscosity has

* Corresponding author. been investigated less thoroughly (the viscositydominated situation). This paper is concerned with experiments in which break-up dominates so that relevant criteria can be tested. To this cnd we performed emulsification experiments with waterin-oil (W/O) emulsions in a stirred vessel with a turbine impeller. The effects of emulsifiers and the dispersed-phase volume fraction on the final droplet size were evaluated.

\section{Theory}

The break-up of droplets depends strongly on the type of flow. Turbulent flow is of a chaotic nature, in contrast to laminar flow which can be 
described by well-defined streamlines. Transitional flow is somewhere in between: in a stirred vessel the flow is generally turbulent near the impeller, while the flow might be laminar at larger distances from the impeller. The type of flow occurring in a certain situation can be derived from the Reynolds number:

$\operatorname{Re}=\frac{\rho L V}{\eta}$

where $L$ is the characteristic length scale, $V$ is the characteristic velocity scale, $\rho$ is the density $\left(\mathrm{kg} \mathrm{m}^{-3}\right)$ and $\eta$ is the dynamic viscosity ( $\mathrm{Pa} \mathrm{s}$ ).

For a stirred vessel the length and velocity scale are based on the impeller diameter and tip speed respectively, giving

$R e_{\text {imp }}=\frac{N D_{\text {imp }}^{2} \rho}{\eta}$

where $R e_{\mathrm{imp}}$ is the Reynolds number based on the impeller, $N$ is the rotational speed of the impeller (rev s${ }^{-1}$ ) and $D_{\text {imp }}$ is the diameter of the impeller (m).

For vessels with a turbine impeller the geometry is usually standardized, e.g. a baffled vessel, the diameter of which equals the height of the emulsion volume and the impeller, might have a diameter equal to one-half or one-third of the diameter of the vessel. In such a geometry the flow will be turbulent in the whole vessel if the Reynolds number based on the impeller exceeds 10000 . The flow will be transitional for Reynolds numbers between 10 and 10000 , while the flow will be laminar for Reynolds numbers below about 10 , as mentioned by Perry [1].

Eq. (2) shows that with an aqueous phase and an impeller diameter of e.g. $0.05 \mathrm{~m}$, the flow will be turbulent in the whole vessel when $N>4 \mathrm{rev}$ $\mathrm{s}^{-1}$, which is a very low impeller speed for emulsification. However, for a triacylglycerol oil the viscosity is 50 times higher and the flow will be transitional for all reasonable impeller speeds. Also in the latter case, break-up occurs in the impeller region and thus in turbulent flow.

The size of the droplets will be determined by the intensity of the turbulent flow, which is characterized by the turbulent energy dissipation rate $\epsilon$, expressed in watts per kilogram (or metres squared per second cubed). The energy dissipation rate averaged over the whole vessel is given by Perry [1]:

$\epsilon_{\mathrm{av}}=P_{0} N^{3} D_{\mathrm{imp}}^{5} / V$

where $P_{0}$ is the dimensionless power number and $V$ is the volume of the vessel $\left(\mathrm{m}^{3}\right)$. Droplet breakup is determined by the maximum energy dissipation rate $\epsilon_{\max }$ prevailing in the impeller region, which will be considerably higher than this average value. Further, the volume of the vessel is proportional to $D_{\text {imp }}^{3}$, which leads to

$\epsilon_{\max }=C_{\text {diss }} N^{3} D_{\text {imp }}^{2}$

The value of $C_{\text {diss }}$ will be discussed in Section 4.1.

Large eddies are formed in the turbulent flow. These large eddies create smaller eddies with increased rotation, due to the conservation of angular momentum. In this way the size of the eddies decreases until an eddy size has been reached at which the energy is dissipated as heat, after which the eddy vanishes. The smallest eddies are called Kolmogorov eddies, after Kolmogorov who developed theories to describe eddy kinetics [2].

An important parameter for the droplet breakup is the length scale $L_{\mathbf{k}}$ of the Kolmogorov eddy, which was approximated by Kolmogorov [2] as

$L_{\mathrm{k}}=\left(v^{3} / \epsilon\right)^{0.25}$

where $v$ is the kinematic viscosity $\left(\mathrm{m}^{2} \mathrm{~s}^{-1}\right)$.

Two mechanisms for droplet break-up in turbulent flows are distinguished. Which of these mechanisms is relevant to a certain situation follows from a comparison between the length scale of the Kolmogorov eddy and the maximum droplet diameter.

Break-up of the droplets will occur by viscous forces when the maximum droplet diameter is small in comparison with the length scale of the Kolmogorov eddy: the break-up process is supposed to occur in the Kolmogorov eddy, similar to that in viscous flows.

In such a flow there are viscous forces which try to deform the droplet. These "forces" are of the order of $\dot{\gamma} \eta_{\mathrm{c}}$, where $\dot{\gamma}$ is the shear rate $\left(\mathrm{s}^{-1}\right)$ and $\eta_{\mathrm{c}}$ is the dynamic viscosity of the continuous phase. These "viscous forces" are opposed by "interfacial 
forces", which try to maintain a spherical shape of the droplet. These "interfacial forces" are of the order of $\sigma / R$, where $\sigma$ is the interfacial tension $\left(\mathrm{N} \mathrm{m}^{-1}\right)$ and $R$ is the droplet radius $(\mathrm{m})$. The ratio of these "viscous forces" and "interfacial forces" is called the capillary number $\Omega$ :

$\Omega=\dot{\gamma} \eta_{\mathrm{c}} R / \sigma$

Break-up occurs if the capillary number $\Omega$ is larger than a critical value $\Omega_{\text {crit }}$ and this criterium depends on the viscosity ratio and the type of flow, as shown in Fig. 1, which contains the data obtained by Bentley and Leal [3]: break-up will occur in the area above the line corresponding to the relevant type of flow, while the droplets below that line are not broken up further. Droplets under conditions just on the line are the largest droplets, which are just not broken up under these conditions.

To express Eq. (6) in terms of turbulence properties a relationship derived by Kolmogorov [2] is applied:

$\dot{\gamma}=\left(\epsilon / \nu_{\mathrm{c}}\right)^{0.5}$

where $v_{\mathrm{c}}$ is the kinematic viscosity of the continuous phase.

Combining Eqs. (6) and (7) leads to an average droplet diameter $D_{3,2}$ :

$D_{3,2}=K_{\mathrm{v}} \sigma\left(\rho \eta_{\mathrm{c}} \epsilon\right)^{-0.5} \Omega_{\text {crit }}$

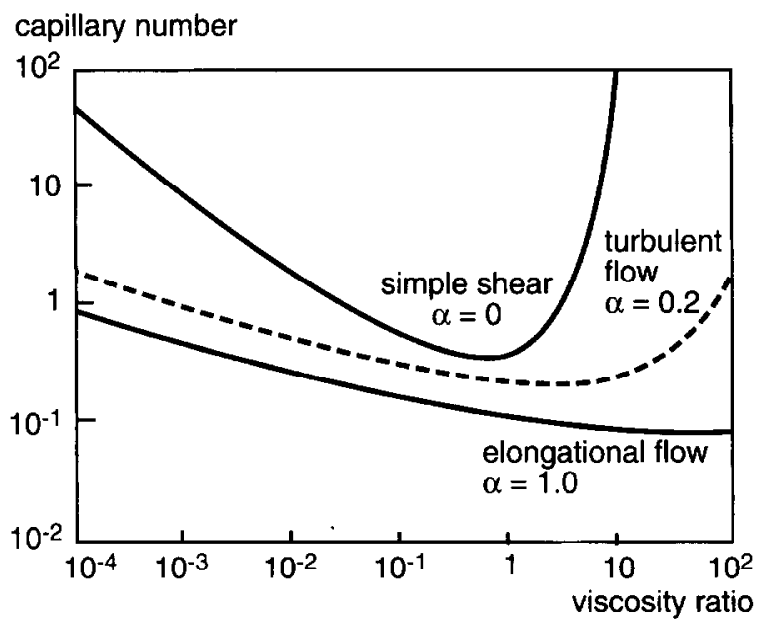

Fig. 1. The capillary number as a function of the viscosity ratio for a few types of flow (data from Bentley and Leal [3]). where $K_{y}$ equals the ratio between $D_{3,2}$ and the radius of the largest droplet which is just not broken up.

The second break-up mechanism, called inertiadominated break-up, becomes relevant when the maximum diameter of the droplet is large in comparison with the length scale of the Kolmogorov eddy. According to this mechanism the droplets are broken up by pressure fluctuations, which are of the order of $\rho U^{2}$, where $U$ equals the velocity fluctuation caused by the eddy. Again " $\sigma / R$ " tries to maintain a spherical shape of the droplet. The ratio of $\rho U^{2}$ and $\sigma / R$ is called the Weber number:

$W e=\frac{\rho U^{2} R}{\sigma}$

Break-up will occur when the Weber number is higher than a critical value. In principle, the average droplet diameter can be derived from Eq. (9), provided that the critical Weber number is determined experimentally, while the turbulent velocity fluctuation can be derived from the eddy properties. This is thus similar to the derivation of the equations for the viscosity-dominated regime. However, for inertia-dominated break-up it is more usual to define another Weber number, which is based on the impeller:

$W e_{\text {imp }}=\rho N^{2} D_{\text {imp }}^{3} / \sigma$

which leads to the following equation, which is frequently applied for dilute emulsions (see, for example, the work of Godfrey et al. [4] and Sharma et al. [5]):

$\frac{D_{3,2}}{D_{\mathrm{imp}}}=K_{\mathrm{i}} W e_{\mathrm{imp}}^{-0.6}$

where $K_{\mathrm{i}}$ is a constant to be determined experimentally. Eqs. (10) and (11) result in

$D_{3,2}=K_{\mathrm{i}} D_{\mathrm{imp}}\left(\frac{\sigma}{\rho D_{\mathrm{imp}}^{3} N^{2}}\right)^{0.6}$

Eq. (12) could of course also be derived via Eq. (9), as shown by Godfrey et al. [4].

The equations mentioned above will be tested experimentally for emulsions containing a continuous phase of high viscosity. Without added emulsifiers the break-up turned out to be at the 
boundary of the viscosity-dominated and inertiadominated regimes. The addition of emulsifiers reduces the droplet size; as a result the viscous regime becomes relevant.

\section{Experimental}

Emulsification was performed in a glass vessel with an inner diameter of $15 \mathrm{~cm}$, which contained four baffles with a width of $1.5 \mathrm{~cm}$. The applied standard turbine impeller had six blades and a total diameter of $5 \mathrm{~cm}$. The height of the emulsion volume was equal to the vessel diameter. The stirrer was placed at one-third of the height of the emulsion fluid, measured from the bottom.

The $\mathrm{W} / \mathrm{O}$ emulsions contained either paraffin oil, which had a viscosity of $72 \mathrm{mPa}$ s, or a triacylglycerol oil of $50 \mathrm{mPa}$. As emulsifiers we used either a polyricinoyl ester of polyglycerol or monooleylglycerol, both of technical grade.

The droplet sizes of rather unstable emulsions were established by microscopical measurements on samples taken. The sizes of individual droplets were compared with a calibrated grid in the ocular. In most cases the results for five samples were combined to give a drop-size distribution. Emulsions containing the polyricinoyl ester of polyglycerol were stable enough under static conditions to use turbidimetry for $D_{3,2}$ assessment. To that end, the emulsions were diluted to $1 \%$ using an oil-emulsifier mixture; subsequently the $D_{3,2}$ value was determined from the extinction of a laser beam passing through the sample.

\section{Results and discussion}

\subsection{The break-up equations in the absence of emulsifiers}

The break-up equations were tested first for emulsions without added emulsifiers. Such a test of the break-up equations can of course only be performed when the effect of coalescence on the droplet diameter is negligible. To that end, emulsions containing only $1 \%$ water in paraffin oil were investigated. It turned out that even at this low volume fraction there was too much coalescence when the small amount of surface-active impurities was removed from the paraffin oil, as will be discussed in a forthcoming paper [6]. However, coalescence was largely eliminated when paraffin oil was used without purification. Under these conditions, the drop size distributions of these cmulsions were found to consist of a single pcak. Measurements were performed when the steady state was reached. The derived values of $D_{3,2}$ are shown in Fig. 2 as a function of the impeller speed.

In order to compare these measured values with theoretical values we had to know the value of the constant in the equation for the maximum energy dissipation rate (Eq. (4)). Although there is some uncertainty about this constant, we estimate that for our geometry the maximum energy dissipation rate is given by

$\epsilon_{\max }=45 N^{3} D_{\mathrm{imp}}^{2}$

The following arguments are presented:

(1) The value of $P_{0}$ in Eq. (3) is about 3.5 for the Reynolds numbers in the present investigation; this in contrast to a value of about 6 , which is relevant for a continuous phase with a low viscosity, as discussed by Perry [1].

(2) In Eq. (3) the volume $V$ of the vessel can be

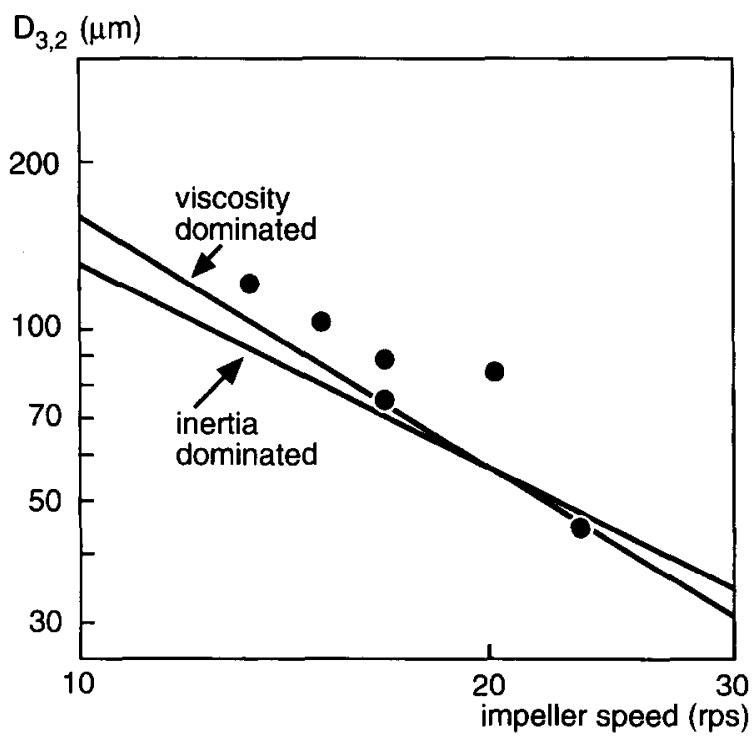

Fig. 2. $D_{3,2}$ for emulsions of $1 \%$ water in paraffin oil. The solid lines are theoretical lines. 
expressed in terms of $D_{\text {imp }}$, as mentioned before. This yields the energy dissipation rate averaged over the whole vessel, but the energy dissipation rate averaged over the impeller region will be considerably larger: a factor of 8 is proposed by Calabrese et al. [7], when the impeller diameter is half the vessel diameter.

(3) In addition it has been suggested by Cutter [8] that the maximum energy dissipation rate occurring somewhere in the impeller region might still be about a factor of 10 higher than the value averaged over the impeller region.

There remains some uncertainty regarding the coefficient of Eq. (13), which will be resolved from the comparison of the measured and calculated $D_{3,2}$ values.

The next step is to determine whether the breakup of water droplets in paraffin oil is viscosity dominated or inertia dominated: in the first regime the maximum droplet diameter is small in comparison with the length scale of the Kolmogorov eddy, while the opposite is true in the inertia-dominated regime, as discussed before. Eq. (5) gives a value of $161 \mu \mathrm{m}$ for the length scale of the Kolmogorov eddy at $20 \mathrm{rev} \mathrm{s}^{-1}$, when Eq. (13) is used for the energy dissipation rate. This length scale roughly equals the maximum droplet diameter. For these emulsions without emulsifier the break-up mechanism is thus somewhere between inertia-dominated break-up and viscosity-dominated break-up. Therefore we have compared in Fig. 2 the measured $D_{3,2}$ values with the values calculated for viscosity-dominated break-up (Eq. (8)) and for inertia-dominated break-up (Eq. (12)). We applied $K_{\mathrm{v}}=0.7$ as measured by Karabelas [9] and $\Omega_{\text {crit }}=$ 0.5 , as can be seen in Fig. 1 . For $K_{\mathrm{i}}$ a value of about 0.06 is frequently measured with low viscosity liquids $[4,5]$, but this value should be corrected for our somewhat smaller power number, which is caused by the larger viscosity of the continuous phase: the corrected value of $K_{\mathrm{i}}$ becomes 0.074 . Fig. 2 shows that the equations for viscositydominated break-up and inertia-dominated breakup predict nearly the same values for the droplet diameters at the applied impeller speeds. There is thus a gradual transition between the two theories. Fig. 2 further shows that there is good agreement between the experimental data and these theoreti- cal predictions; this shows that Eq. (13) gives a reasonable estimate of the maximum energy dissipation rate.

\subsection{Droplet diameters in the presence of an emulsifier}

Emulsions of $1 \%$ water in triacylglycerol oil containing an emulsifier were investigated. Microscopical measurements showed a bimodal drop size distribution: in addition to the usual "coarse" droplets there were now a very large number of very small droplets of about $1.5-2 \mu \mathrm{m}$; the number of these very small droplets was mostly about one hundred times as large as the total number of the "coarse" droplets. This bimodal size distribution indicates that two different break-up mechanisms occur. This phenomenon is illustrated in Figs. 3 and 4 where the average diameters of the full distribution and of the "coarse part" of the

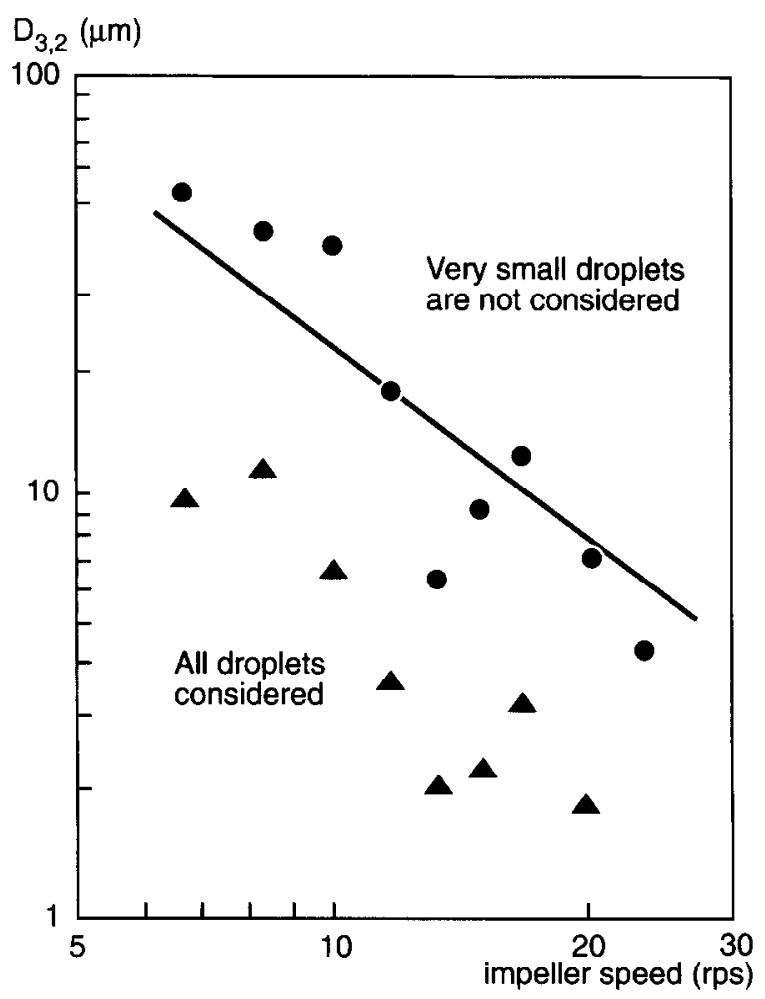

Fig. 3. $D_{3,2}$ for $1 \% \mathrm{~W} / \mathrm{O}$ emulsions with $1 \%$ of the polyricinoyl ester of polyglycerol in triacylglycerol oil. Solid line: theory (viscous break-up). 


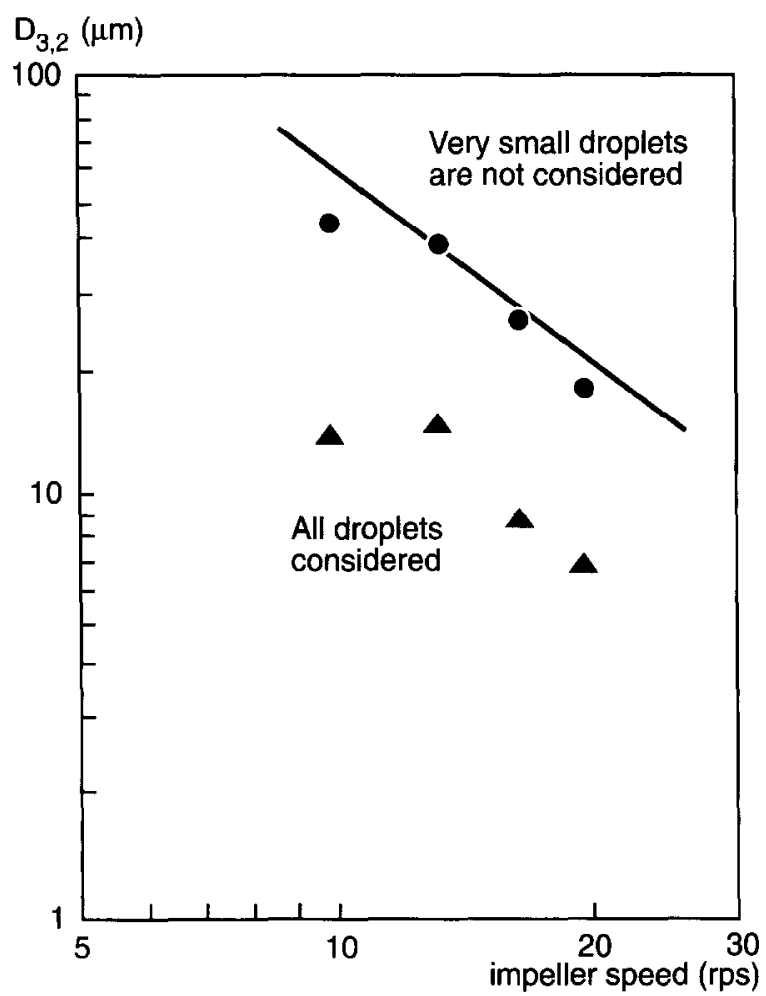

Fig. 4. $D_{3,2}$ for $1 \% \mathrm{~W} / \mathrm{O}$ emulsions with $0.8 \%$ monooleylglycerol in triacylglycerol oil. Solid line: theory (viscous break-up).

distribution are plotted for emulsions containing $1 \%$ of the polyricinoyl ester of polyglycerol or $0.8 \%$ monooleylglycerol respectively.

We investigated whether the "coarse part" of the size distribution can be described by the break-up relations. For these emulsions the break-up is viscosity dominated, as the droplet diameter is considerably reduced by the addition of the emulsifier. In principle, Eq. (8) should therefore hold if the theory, as developed for emulsions without emulsifier, can also be applied in the presence of emulsifiers. This requires a discussion of the relevant value of the interfacial tension, which has to be introduced in Eq. (8). The problem is that the interface of the droplet increases during the deformation of the droplet, which occurs prior to the break-up. This increase of the interface temporarily decreases the adsorption of the emulsifier, which increases the interfacial tension to a value which is larger than the equilibrium interfacial tension. This will be opposed by transport of emulsifier out of the continuous phase. A first-order calculation indicated that such a transport is relatively fast. This implies that the transport of emulsifier to the interface might be sufficiently fast to maintain a (nearly) constant interfacial tension during the deformation and break-up of the droplet. We therefore investigated whether the equilibrium interfacial tension can be applied for calculating the droplet diameter.

In Eq. (8) the equilibrium interfacial tensions, relevant to Figs. 3 and 4 respectively, were therefore introduced and the calculated droplet diameters are presented in these graphs by the solid lines; this shows that the calculated values are in very good agreement with the measured $D_{3,2}$ value of the "coarse part" of the distribution.

In addition, a very large number of very small droplets were obtained which cannot be due to satellite droplets from the break-up process, as the number is far too large. It could well be the result of tip streaming where the flow displaces the emulsifier to the tip of the deformed droplet, which makes the interfacial tension there locally very small. This results in a stream of very small droplets at the tip of the deformed droplet. Tip streaming has often been observed in the literature; it was studied under model conditions by de Bruijn [10], who found two requirements: the viscosity of the dispersed phase should be considerably smaller than the viscosity of the continuous phase and an emulsifier should be present. However, the emulsifier might also be a surface-active impurity: minor concentrations might already result in tip streaming. A quantitative model for tip streaming is not yet available.

In conclusion, the "coarse part" of the size distribution was well described by the break-up relations. However, the very small droplets induce a considerable decrease in the $D_{3,2}$ value of the total size distribution. A comparison of the $D_{3,2}$ value obtained from the full distribution with that of the break-up relationships is therefore not useful.

\subsection{Time scale for break-up}

Another technologically important aspect is the time-scale of the break-up process in a stirred vessel. On making a $\mathrm{W} / \mathrm{O}$ emulsion the initial 
dispersion of the water into coarse droplets is found to occur fast, while further decrease of the droplet diameter required a considerable time, as shown in Fig. 5 for a 30\% W/O emulsion. Similar results were obtained for other volume fractions. At a given impeller speed, a variation in the volume fraction did not change the time scale of the droplet size evolution. As the average circulation time is of the order of $1 \mathrm{~s}$, the droplets have to pass the impeller region a few thousand times before the equilibrium droplet diameter is reached. Similar results are found by Chatzi et al. [11], Apostolidou and Stamatoudis [12], who also give more references concerning such long time scales, and by Stamatoudis [13].

Fig. 5 shows that plots of $\log D_{3,2}$ versus $\log t$ are linear in the transient period. Similarly, plots of $\log D_{3,2}$ versus $\log N$ are linear, as shown by Figs. 2-4. We therefore plotted the values of $D_{3,2}$ during the transient period and for various impeller speeds in a single plot. It turned out that the $D_{3.2}$ values could be scaled according to $D_{3,2} \propto N^{-1.5} \times t^{-0.33}$, which holds over a large

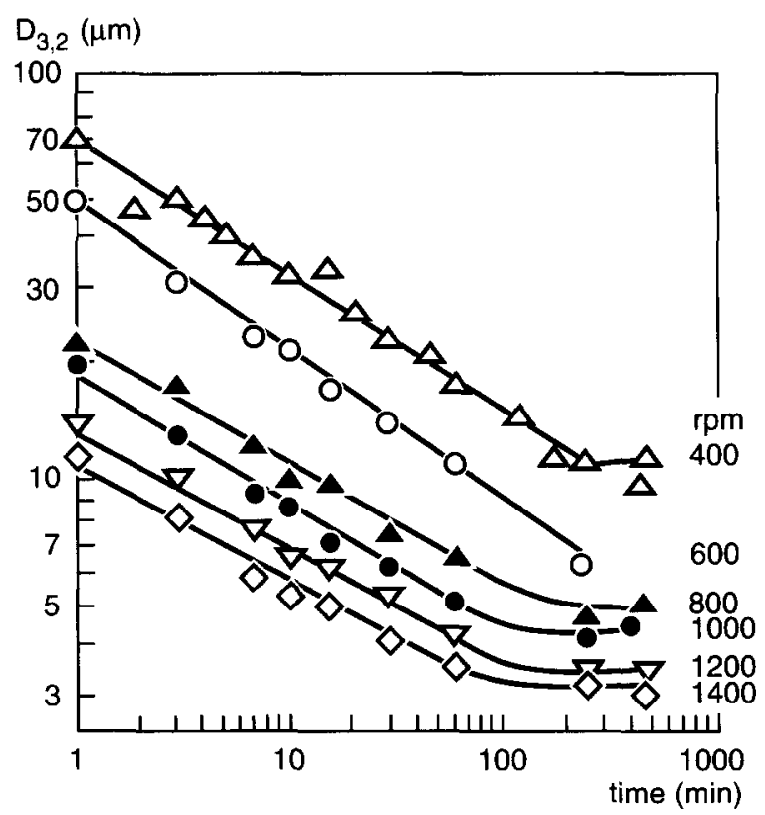

Fig. 5. $D_{3,2}$ as a function of time for emulsions of $30 \%$ water in triacylglyecrol oil containing $2 \%$ of the polyricinoyl ester of polyglycerol. The impeller speeds are indicated. volume fraction range. The exponent of the impeller speed again suggests that the break-up process is viscosity dominated.

The origin of this time scale is not fully clear yet. It might be that the break-up occurs in intense eddies which occur only in a small volume near the impeller. These eddies exist only during a very small period, so that possibly cooperative effects of subsequent eddies are required for break-up. It might also be that break-up occurs in the boundary layer of the impeller, which has a small volume as well. The stochastic nature of the process is the origin of the time scale as the whole vessel volume has to pass these zones before a steady state is reached.

The steady-state droplet sizes for the emulsions from Fig. 5 and for other dispersed-phase volume fractions are depicted in Fig. 6. The results show that the $D_{3,2}$ value decreased with rotational speed and that the size was barely dependent on the volume fraction, indicating that the process under consideration is a one-droplet event (break-up) and that the conditions do not change with increas-

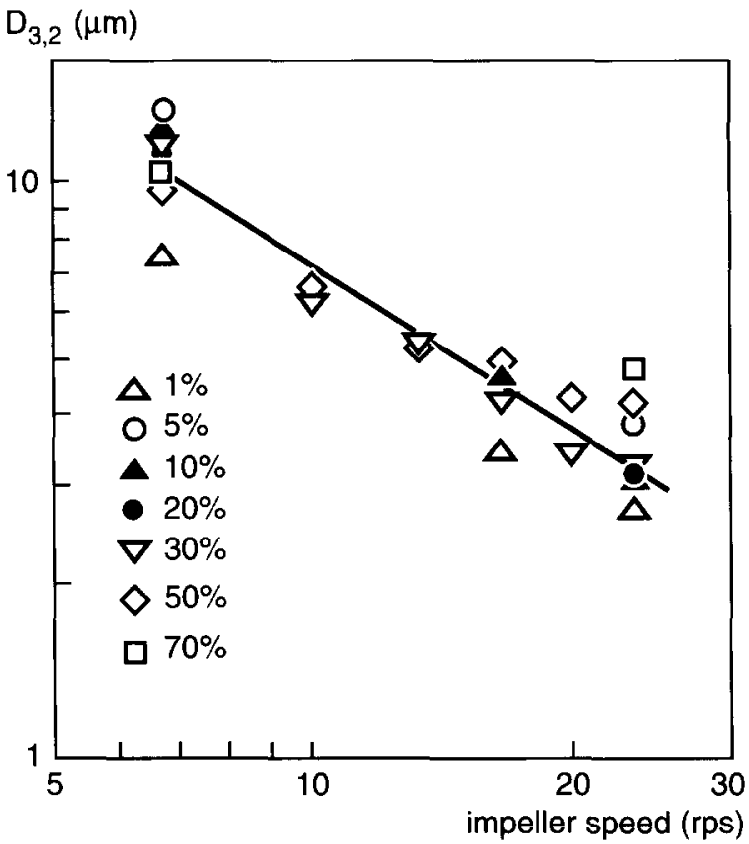

Fig. 6. $D_{3,2}$ for emulsions with various volume fractions of water in triacylglycerol oil containing $2 \%$ of the polyricinoyl ester of polyglycerol. 
ing volume fraction. These findings are contrary to results obtained for non-stabilized emulsions, where $D_{3,2}$ increases with volume fraction, as a result of a balance between break-up and coalescence.

\section{Conclusions}

In emulsions without emulsifiers added the steady state droplet diameters were found to be in agreement with predicted values. Emulsions containing emulsifier showed a bimodal size distribution with a very large number of very small droplets. The steady state average diameter of the "coarse part" of the size distribution was reasonably well described using the droplet break-up relations for viscosity-dominated break-up, provided that the equilibrium interfacial tension was applied. This indicates that the transport of emulsifier was sufficiently fast to maintain (nearly) equilibrium adsorption during the deformation of the droplet. The very small droplets of the distribution are expected to be formed by tip streaming.

\section{References}

[1] Perry's Chemical Engineers Handbook, 6th ed. R.H. Perry and D.W. Green (Eds.), Green, New York, 1984.

[2] A.N. Kolmogorov, Dokl. Akad. Nauk. SSSR, 30 (1941) 301; 31 (1941) 538; 32 (1941) 16.

[3] B.J. Bentley and L.G. Leal, J. Fluid Mech., 167 (1986) 241.

[4] J.C. Godfrey, F.I.N. Obi and R.N. Reeve, Chem. Eng. Prog., 85(12) (1988) 61.

[5] S.K. Sharma, A.N. Goswami and B.S. Rawat, Indian J. Technol., 29 (1991) 254.

[6] F. Groeneweg and W.G.M. Agterof, in preparation.

[7] R.V. Calabrese, T.P.K. Chang and P.T. Dang, Am. Inst. Chem. Eng. J., 32 (1986) 657.

[8] L.A. Cutter, Am. Inst. Chem. Eng. J., 12 (1966) 35.

[9] A.J. Karabelas, Am. Inst. Chem. Eng. J., 24 (1978) 170.

[10] R.A. de Bruijn, Chem. Eng. Sci., 48 (1993) 277.

[11] E.G. Chatzi, C.J. Boutris and C. Kiparissides, Ind. Eng. Chem. Res., 30 (1991) 536.

[12] C. Apostolidou and M. Stamatoudis, Chem. Ing. Tech., 63 (1991) 66

[13] M. Stamatoudis, Thesis, Illinois Institute, Chicago, 1977. 